\title{
Formação de professores Guarani e Kaiowá: interculturalidade e decolonialidade no ensino de matemática
}

\author{
Guarani and Kaiowá teacher education: interculturality and decoloniality in \\ mathematics teaching
}

\author{
Maria Aparecida Mendes de Oliveira ${ }^{1}$ \\ Jackeline Rodrigues Mendes ${ }^{2}$
}

\begin{abstract}
Resumo
O presente artigo propõe uma reflexão sobre as relações entre saberes (matemáticos) de diferentes matizes/origens, provenientes das práticas culturais de um determinado grupo étnico e do mundo acadêmico e escolar, no processo de formação inicial de professores indígenas, bem como na formação continuada, a partir de sua inserção nos anos finais do Ensino Fundamental e no Ensino Médio em escolas indígenas de suas comunidades. A reflexão aqui apresentada é sustentada em estudos sobre interculturalidade e decolonialidade do saber. Partimos da fala de professores Guarani e Kaiowá, em Mato Grosso do Sul, egressos do curso de Licenciatura Intercultural Indígena da Universidade Federal da Grande Dourados-UFGD. As falas destes profissionais da educação revelam os tensionamentos produzidos nessas relações e coloca em questionamento a lógica de hierarquização entre os saberes presentes no modelo de colonialidade. As relações entre saberes, estabelecidos no modelo imposto pelas estruturas, pelos sistemas de poder e pelos conhecimentos coloniais, mantidos e reproduzidos nos espaços institucionais, são colocadas em questão com a presença dos indígenas na universidade e nas escolas indígenas. E esta presença configura como processo de resistência a este modelo. Desta forma, interculturalidade e a decolonialidade são projetos que estão ligados à luta por uma escola indígena diferenciada, e sempre em construção, permeada por uma série de tensões.
\end{abstract}

Palavras-chave: formação de professores indígenas; etnomatemática; interculturalidade; decolonialidade

\begin{abstract}
The present article proposes a discussion about relations between knowledge (mathematics) in process of initial formation of indigenous teachers, as well as in the continuous formation with the insertion of these teachers in the Final Years of Elementary and Secondary Education in indigenous schools of their communities. The discussion is presented from studies on interculturality and knowledge decoloniality. We started from the speech of Guarani and Kaiowá teachers, in Mato Grosso do Sul, graduates of the Indigenous Intercultural Licentiate course of the Federal University of Grande Dourados-UFGD. The statements of these teachers reveal the tensions produced in these relations and place in a logical question of hierarchy among the knowledge present in the model of coloniality. The relations between knowledge, established in the model imposed by structures, power systems and colonial knowledge, maintained and reproduced in the institutional spaces, are put in question with the presence of indigenous in university and indigenous schools that is configured as a process of
\end{abstract}

\footnotetext{
${ }^{1}$ Doutoranda em Educação pela Universidade de São Paulo, Professora da Universidade Federal da Grande Dourados-UFGD, Faculdade Intercultural Indígena-FAIND, Brasil. Email: liamendeso@yahoo.com.br

2 Doutora em Linguística Aplicada pela Universidade Estadual de Campinas, Professora da Universidade Estadual de Campinas, Faculdade de Educação, Brasil. Email: jamendes@unicamp.br.
} 
DOI: https://doi.org/ 10.20396/zet.v26i1.8650893

resistance to this model. In this way, interculturality and decoloniality are projects that are linked to struggle for a differentiated indigenous school, always under construction, permeated by a series of tensions.

Keywords: indigenous teacher education; interculturality, ethnomathematics; interculturality; decoloniality

\section{Introdução}

O encontro entre saberes provenientes das práticas culturais de um determinado grupo étnico, e saberes pautado na relação entre cultura europeia e outras, que segue ainda numa relação de dominação colonial (Quijano, 1992), tem gerado tensões para a instituição universitária quando tratamos da formação específica, diferenciada e intercultural de professores indígenas. Pois, se coloca em situação de diálogo, em uma proposta intercultural, os conhecimentos produzidos por comunidades indígenas, e o conhecimento acadêmico e escolar. Além disso, estas tensões também se revelam nas escolas indígenas, em que está posto a necessidade de um lugar, no seu interior, para essas diferentes lógicas de saber e de conhecer.

O diálogo decorrente da ação entre diferentes formas de conhecimentos - os produzidos por diferentes povos e os conhecimentos que se apresentam escolarizados - tem influenciado no ensino de matemática nas escolas indígenas e na formação de professores indígenas. Ao tomarmos como referência o diálogo de forma equitativa entre diferentes conhecimentos, diferentes pessoas, diferentes práticas e formas de compreensão, de acordo com Tubino (2002), pressupomos que lidamos com cenários interculturais.

A escola indígena se constitui, hoje, como um espaço onde diferentes práticas culturais estão em diálogo. Mas é um diálogo que gera tensões no encontro entre saberes, de forma assimétrica (Monteiro e Mendes, 2014). Os programas curriculares ${ }^{3}$ que se desenvolvem nas escolas indígenas são os mesmos que no restante do país. O que se percebe é que, por meio do currículo, continua havendo sobreposição do conhecimento ocidental sobre o conhecimento indígena nas escolas. Este se configura como um instrumento de colonialidade de saber. Para Walsh (2004), a colonialidade do poder passa para o campo do saber, descartando a noção do indígena como intelectual, como alguém que pode intervir diretamente na produção de conhecimento. E, como parte essencial desta colonialidade do saber, é que se mantém a hegemonia do eurocentrismo enquanto perspectiva única do conhecimento.

A educação intercultural e bilíngue, concebida e proposta pelos povos indígenas, como prática de enfrentamento às políticas educativas integracionistas, homogeneizantes, colonizantes, bem como às reformas desiguais de poder, tem um caráter claramente identitário e político reivindicativo (Walsh, 2004). Neste sentido, apresentam-se diferentes desafios para as universidades que se propõem a ofertar uma formação diferenciada e intercultural de professores indígenas que atuam nas escolas das aldeias. Dentre eles, o que mais tem desestabilizado as estruturas vigentes é o movimento de se estabelecer um

\footnotetext{
${ }^{3}$ Os programas curriculares das escolas indígenas seguem a mesma lógica das demais escolas, tanto no que diz respeito à organização do espaço tempo da escola, como a forma em que os conhecimentos estão organizados em "disciplinas". A inserção de componentes curriculares como "cultura indígena" ou a própria "língua indígena" também seguem a lógica disciplinar de organização.
}

Zetetiké, Campinas, SP, v.26, n.1, jan./abr.2018, p.167-184

ISSN 2176-1744 
permanente diálogo entre diferentes significados de mundo, apresentados pelas instituições envolvidas nesse processo, no caso a universidade, as secretarias de educação e as comunidades indígenas. Este desafio tem sido enfrentado por povos indígenas em todo o Brasil, juntamente com pesquisadores de diversas áreas de conhecimento.

A respeito da escolarização dos povos indígenas e sobre a formação de professores indígenas em todo o Brasil, Silva (2001) e Grupioni (2002), destacam nos trabalhos acadêmicos, nas últimas décadas, uma crescente discussão, principalmente no que se refere às áreas de Ciências Sociais, Linguística e Educação. Nesta perspectiva é possível encontrar diversas dissertações e teses ligadas à área da Educação Matemática. Dentre esses trabalhos, podemos identificar diferentes produções que estão voltadas para a discussão em torno da educação escolar indígena e formação de professores indígenas (Mendes, 1995, 2001, 2007; Oliveira, 2009; López Bello, 2000; Correa, 2001; Domingues, 2007; Leite, 2014; Mendonça, 2007; Brito, 2012).

As reflexões a seguir, com foco na discussão sobre a formação de professores indígenas e o diálogo entre saberes, são provenientes de pesquisa em andamento que temos realizado junto à formação de professores guarani e kaiowá, em Mato Grosso do Sul. Partimos de análise das produções realizadas durante períodos de formação inicial de professores indígenas em um curso de Licenciatura Intercultural Indígena, e em oficinas de formação continuada. As falas foram registradas e transcritas e posteriormente apresentadas para os interlocutores, que são professores indígenas.

\section{Os processos de escolarização: da escola para o indígena à apropriação das escolas pelos indígenas}

No Brasil, os povos indígenas vêm passando por um intenso contato com a sociedade envolvente, o que traz para eles muitas transformações em seu modo de organização econômica, social, política e cultural. Nesse processo, a escola tem assumido papel fundamental, pelo fato de atuar como instituição a serviço dos processos de colonização.

No decorrer do processo de colonização e de escolarização dos povos indígenas, destacamos, grosso modo, uma história que vai da inserção das escolas nas comunidades indígenas à apropriação da escola por parte deles. Ferreira (2001) divide esta história em quatro modelos, que vão da escola para o índio à apropriação da escola pelos índios em busca da educação escolar indígena, intercultural e bilíngue. Inicialmente, segundo a autora, este processo de escolarização deu-se no Brasil Colônia, onde a escolarização sistemática dos índios, com viés colonizador, esteve a cargo das missões jesuíticas. Segundo Meliá (1979, p. 43), neste período "o desejo de educar o índio aparece mais definido quando o anseio de submeter o indígena passou a ser o elemento central da ideologia dominante no mundo colonial lusitano".

No Brasil pós colônia, a educação passou a ser pautada por políticas que visam integrar os indígenas à sociedade nacional. $\mathrm{O}$ modelo integracionista, marcado pela criação do Serviço de Proteção aos Índios (SPI), posteriormente FUNAI, foi fortemente influenciado 
pelo Summer Institute of Linguistics (SIL) ${ }^{4}$, pautados no discurso de uma educação bilíngue. Entretanto, o papel da língua indígena na escola servia apenas como uma ponte para alcançar o domínio da língua da portuguesa, caracterizando-se, desse modo, como um modelo de educação bilíngue de transição (Mendes, 2007, Parra et al. 2016).

Um terceiro modelo emerge a partir do surgimento das organizações indígenas dos movimentos de professores indígenas, no período da ditadura militar. A década de 1970 foi marcada pela formação de projetos alternativos de educação escolar bilíngue e intercultural, com a participação de organizações não-governamentais e Universidades, entre outras, e a promoção de encontros de educação para índios. As relações dos povos indígenas com a sociedade civil são construídas numa nova ótica, juntamente com organizações nãogovernamentais, de maneira a estabelecer novos horizontes sociais e políticos, em contrapartida às políticas indigenistas do estado brasileiro até então desenvolvidas ao longo dos séculos.

O quarto modelo é marcado pela iniciativa dos povos indígenas em definir e autogerir a educação formal empreendida nas áreas indígenas, num processo de autoria, que envolve a participação indígena na produção dos currículos e de materiais específicos voltados para as escolas indígenas. É um modelo de autoria que se configura pelas experiências de autonomia e de apropriação da escola pelos povos indígenas. É marcado por um retorno às tradições locais, à língua própria, aos saberes próprios. Como afirma Certeau (2005), isso acontece como algo que já havia se tornado estranho, ou seja, depois de todo processo de colonização, com fortes alterações na ordem social, política e econômica destes povos, retorna-se a algo que é ainda seu (um meio de se identificar). No entanto, já outro, alterado por esta intensa relação estabelecida entre sociedades de culturas diferentes, uma vez que o sentimento de ser diferente está ligado à designação dessa diferença pelos outros.

Cabe observar que a dominação cultural assume características próprias em cada um destes modelos, em cada momento do processo de colonização desses povos. Ferreira (2001) ainda destaca que os processos de dominação ocorridos durante a escolarização dos povos indígenas não são distintos uns dos outros, pois muitos dos objetivos apresentados em uns estão presentes em outros, bem como muitos elementos das duas fases iniciais ainda são vigentes nas práticas educativas em escolas indígenas.

O movimento político e de autoria provocou uma mudança da relação do Estado Brasileiro com os povos indígenas, com a promulgação da Constituição de 1988. Estas mudanças decorrem da forma como o texto da lei aborda o indígena na sociedade brasileira,

\footnotetext{
4 “A missão evangélica americana Summer Institute of Linguistics (SIL), criada no México na década de 1930, expandiu-se na América Latina por meio de alianças com intelectuais latino-americanos e não com o apoio das igrejas evangélicas locais (Stoll, 1985). A missão teve como política manter 'padrinhos', 'protetores' ou 'patronos' entre políticos e intelectuais, tais como Lázaro Cardenas no México, Vargas Liosa no Peru e Darcy Ribeiro no Brasil. [...] é uma missão evangélica especialista na tradução do Novo Testamento para línguas ágrafas. A tradução configura um padrão de evangelização próprio para comunidades rurais pequenas, falantes de línguas ágrafas e que conservam o predomínio da comunicação 'face a face' [...]. (Barros, 2004, p. 47).
} 
colocando-o num outro lugar, no lugar de cidadão de direito. É reconhecido aos índios o direito a "sua organização social, costumes, línguas, crenças e tradições" (art. 231, parágrafo do $1^{\circ}$ ao $7^{\circ}$ ), e seu direito originário à terra.

No que tange à educação escolar, a Constituição Federal de 1988 reconhece, em seus diferentes artigos, "a utilização da língua materna e processos próprios de aprendizagem", bem como seus "modos de criar, fazer e viver" como patrimônio cultural imaterial (art. 210, parágrafo $2^{\circ}$ e artigo 216). Todo o apanágio legal sobre a Educação Escolar Indígena (EEI) surgido após a promulgação da Constituição Federal de $1988^{5}$, seguida da nova Lei de Diretrizes e Bases da Educação Nacional, Lei n. 9.394/96, marcam a reforma educacional ao longo dos anos de 1990, entrando no século XXI e nos dá a dimensão do projeto nacional para uma educação específica e diferenciada que possibilita, para a Educação Escolar Indígena - EEI, o estabelecimento de um espaço de manifestação de diferentes formas de conhecimento.

No entanto, há uma luta constante pela apropriação das escolas indígenas pelos indígenas, pelo reconhecimento da escola enquanto espaço de resistência em que se encontram as populações indígenas. É nesse cenário que se estabelecem vários projetos de formação de professores indígenas. No primeiro momento, voltado para os anos iniciais do Ensino Fundamental. E no segundo momento, a proposição de cursos de Licenciaturas Interculturais.

\section{Os cursos de formação para professores indígenas}

Por meio do conjunto de medidas legais, a Educação Escolar Indígena passa a fazer parte do sistema nacional de educação e deixa de estar a cargo do órgão indigenista oficial (FUNAI), ficando sob a responsabilidade dos Estados e Municípios. Também a partir da reivindicação dos indígenas, num crescente processo de autonomia, aumenta a demanda de escolas nas aldeias e de professores indígenas. Em consequência, vários projetos de formação específica de professores indígenas, em nível de magistério, foram implementados por todo o país.

Destacamos aqui o Projeto Tucum, em Mato Grosso; o Projeto Uhitup, em Minas Gerais; o Projeto de Educação Tikuna, no Estado do Amazonas; o projeto de Formação de

\footnotetext{
${ }^{5}$ Decreto presidencial n 26 de 1991, que inclui as escolas indígenas no Sistema Nacional de Educação; a Lei de Diretrizes e Base da Educação - LDB 9.394/96 que nos artigos 26, 32, e mais especificamente nos artigos 78 e 79; o Parecer 14/99 - Conselho Nacional de Educação - 14 de setembro de 1999; a Resolução 03/99 - Conselho Nacional de Educação - 10 de novembro de 1999, que entre outras definições, cria a categorias de Escola Indígena; o Plano Nacional de Educação (Lei 10.172 - 9 de janeiro de 2001) que traz um Capítulo sobre Educação Escolar Indígena; Decreto Presidencial 6.861 de 2009, que aborda a organização territorial da educação escolar sob a definição de territórios etnoeducacionais; a Resolução N ${ }^{o}$ 5, de 22 de junho de 2012 que estabelece as Diretrizes Curriculares Nacionais para a Educação Escolar Indígena na Educação Básica e os Referenciais Para a Formação de Professores Indígenas (2001); Resolução $N^{o} 2$, de $1^{o}$ de julho de 2015, que define as Diretrizes Curriculares Nacionais para a formação inicial em nível superior (cursos de licenciatura, cursos de formação pedagógica para graduados e cursos de segunda licenciatura) e para a formação continuada.
} 
Professores do Parque Indígena do Xingu, Mato Grosso; o Programa de Magistério Intercultural da CIP-AC, no Acre; o Curso Normal Médio Ára Verá, em Mato Grosso do Sul, dentre muitas outras experiências desenvolvidas a partir de parcerias entre Estados, Universidades e organizações não governamentais. A partir destas iniciativas, passou-se à discussão da criação de cursos de formação específica em nível superior.

Os programas de formação de professores indígenas possuem propostas pedagógicas e curriculares próprias, constituídas em relações tensas. Segundo Monte (2000, p. 21), essas tensões são geradas por se tratar de uma educação numa perspectiva intercultural:

[...] experimentada em contextos indígenas, há séculos confrontadas por dominação e assimetria com os Estados e sociedades nacionais, a ênfase afetiva no que chamam de 'próprio' e de 'cultura tradicional' dá ao discurso dos professores um forte viés ideológico e, aos procedimentos didáticos, uma indispensável metodologia indutiva: a base e a vértebra dos processos aquisitivos estão assentadas na cultura e na língua própria, de onde devem advir, por nexos históricos e conexões discursivas permanentes, os novos conhecimentos comuns a outras sociedades, apropriados também pela intercomunicação na escola.

A oferta de cursos superiores específicos para populações indígenas, parte de um forte movimento que ocorre em toda a América Latina, visando à formação de professores índios na perspectiva da Educação Intercultural e Bilíngue. Muitas organizações, como a Fundação PROEIB Andes ${ }^{6}$, a Rede Interamericana de Formação de Formadores em Educação Indígena (RIF-FOEI $)^{7}$, entre outras, discutem e realizam ações em torno da educação bilíngue e intercultural, em busca de fortalecer as diversas formas de pensamento educacional, com e para os povos indígenas, tendo em vista satisfazer as crescentes necessidades e demandas por mais e melhor educação escolar indígena, tendo como ponto forte a participação política indígena.

O fortalecimento dos movimentos sociais indígenas em toda a América Latina traz à tona novos paradigmas que regem a educação, apresentadas pelas organizações indígenas. Estas têm se empenhado em estabelecer as bases para uma política da diferença, como também para uma educação intercultural e bilíngue própria que satisfaça as necessidades políticas de suas sociedades. Para Prada e Lopes (2004, p.30), “Os indígenas latinoamericanos colocam com clareza suas necessidades a respeito das transformações que a

\footnotetext{
${ }^{6}$ O Programa Acadêmico PROEIB Andes, dependente da Decanatura da Faculdade de Ciências Humanas e Educação em Ciências da Universidad Mayor de San Simón, é uma parte integrante da sua Licenciatura, Departamento que tem como objetivo prosseguir com os processos de formação dos recursos regionais humanos indígenas. Teve início em 1996, bem como programas e projetos de investigação sobre currículos e programas curriculares.

${ }^{7}$ A (RIF-FOEI) é um consórcio constituído por universidades, instituições públicas e organizações indígenas provenientes de sete países e de cinco regiões da Organização Universitária Interamericana (OUI), dentre elas: Universidad Pedagógica Nacional Mexique e Secretaría de Educación Pública Educación Intercultural Bilingue no México; Programa de Formación en Educación Intercultural Bilingue para los Países Andinos (PROEIBANDES) na Bolívia; University of Regina no Canadá; Consejo Regional de Indígenas del Cauca na Colômbia; Fundación Defensoría Kichwa de Cotopaxi Fudeki no Equador; Universidad Regiones Autónomas de la Costa Caribe Nicaragüense (URACCAN) na Nicarágua; Universidad Nacional Agraria La Molina no Peru.
}

Zetetiké, Campinas, SP, v.26, n.1, jan./abr.2018, p.167-184

ISSN 2176-1744 
educação deve experimentar para responder ao desafio contemporâneo de uma interculturalidade que articule e dê conta da história multicultural latino-americana".

No Brasil, vários cursos em nível superior de formação de professores indígenas foram implantados nesta perspectiva. As primeiras experiências foram o Terceiro Grau Indígena de Barra do Bugres, implantado pela Universidade Estadual de Mato Grosso e o Curso Insikiran, da Universidade Federal de Roraima.

Nas últimas décadas foram implantados cursos de formação de professores indígenas em nível superior em vários Estados do Brasil, dentre eles, o Curso de Licenciatura Intercultural Indígena, da Universidade Federal de Goiás (UFG); o Curso para Educadores Indígenas, da Universidade Federal de Minas Gerais (UFMG); o Curso de Licenciatura Indígena no Contexto dos Guarani e Kaiowá (Teko Arandu), da Universidade Federal da Grande Dourados (UFGD), no Estado de Mato Grosso do Sul; o Curso de Licenciatura Específica para Professores Indígenas do Alto Solimões, da Universidade do Estado do Amazonas (UEA); o Curso de Licenciatura em Educação Escolar Indígena da Universidade Federal do Amapá (Unifap), dentre outros, que somam hoje cerca de 26 cursos de Licenciatura Intercultural pelo Brasil.

\section{Formação de professores indígenas Guarani e Kaiowá de matemática e a relação entre os saberes.}

Nesse cenário, de uma educação intercultural e bilíngue, nossa proposta é discutir as relações que se estabelecem entre os saberes no contexto da formação de professores indígenas Guarani e Kaiowá, formados por um curso de Licenciatura Intercultural Indígena, em particular na habilitação em Matemática, que atuam em escolas indígenas da região sul de Mato Grosso do Sul.

As comunidades indígenas que se encontram no sul do estado de Mato Grosso do Sul são compostas, em sua grande maioria, por povos Guarani Ñandeva e Guarani Kaiowá ${ }^{8}$, falantes da mesma língua: o Guarani. Como apresenta Schadem (1974, p. 2), os Guarani do Brasil Meridional podem ser divididos em três grandes grupos: os Nandéva, os Mbyá e os Kaiowá. A sociedade indígena Guarani, em Mato Grosso do Sul, é representada pelos Ñandéva e Kaiowá. Nesse Estado, a população guarani e kaiowá é de, aproximadamente, 50.000 pessoas, distribuídas em 29 áreas indígenas localizadas em 17 municípios do Sul do Estado $^{9}$, sendo os Kaiowá a maioria. As áreas ocupam, hoje, um território de $40.697^{10}$ hectares, aproximadamente.

\footnotetext{
${ }^{8}$ Utilizaremos, no decorrer do texto, a designação Guarani para os povos Guarani Nandeva e Kaiowá para os Guarani Kaiowá, dada a forma como se autodenominam.

${ }^{9}$ Fonte: Projeto Criança Kaiowá e Guarani em Mato Grosso do Sul: a realidade na visão dos índios/organizadoras: Adir Casaro Nascimento, Suzana Gonçalves Batista e Suzi Maggi Kras. Campo Grande: UCDB, 2005.

${ }^{10}$ Estão incluídas nesse levantamento apenas as áreas demarcadas. Algumas dessas áreas ainda não foram demarcadas e encontram-se em situação de conflito.
} 
DOI: https://doi.org/ 10.20396/zet.v26il.8650893

Figura 1: Mapa de localização das terras indígenas Guarani e Kaiowá

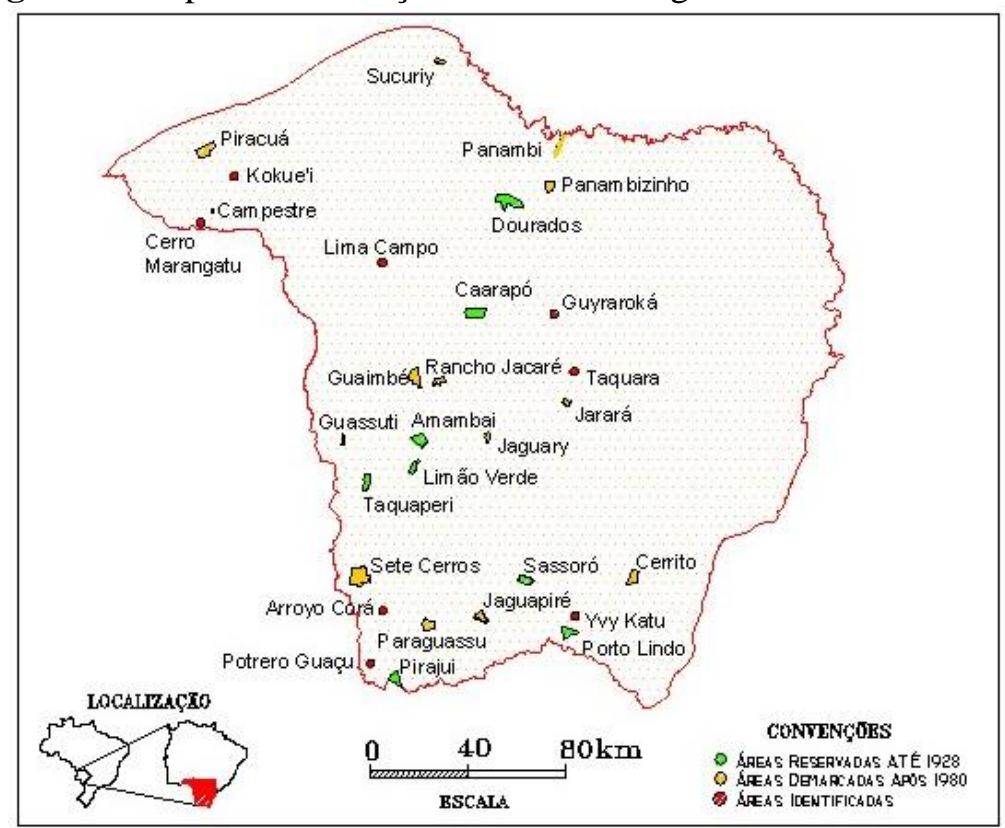

Fonte: http://www.trilhasdeconhecimentos.etc.br/mato_grosso_do_sul/images/guarani_02.jpg

$\mathrm{Na}$ atualidade, os Guarani e Kaiowá passam por um intenso e brutal histórico de contato (Schaden, 1974), trazendo para esta sociedade indígena muitas transformações com relação ao seu modo de organização. As práticas da caça, da pesca e da coleta já não são mais possíveis para estes povos, já que o processo de exploração e devastação da vegetação nativa foi muito intenso. Atualmente são as lavouras de soja, cana e pastagem para a criação de gado dominam que dominam a paisagem no entorno das áreas indígenas.

Um dos grandes problemas enfrentados pelos Kaiowá e Guarani é a questão da terra, pois estes se encontram em pequenas áreas, nas reservas que foram criadas em virtude da ocupação da terra por fazendas. Na cultura Kaiowá, a relação com a terra tem a ver com seu modo de ser e de viver, o Teko. O Guarani refere-se a seu território como tekoha. Para eles "teko é o modo de ser, o sistema, a cultura, a lei e os costumes, o tekoha é o lugar e o meio em que se dão as condições de possibilidade do modo de ser Guarani” (Meliá, apud Vietta, 1989, p. 336). Na busca por garantir o seu teko, os indígenas enfrentam, desde a década de 1980, uma luta pela retomada de seus territórios tradicionais.

As transformações enfrentadas por estes povos, ao longo dos tempos, trazem a necessidade de buscarem outras formas de se relacionar com a sociedade do entorno, num movimento de diálogo entre culturas. Nesse processo, a escola tem assumido papel fundamental, pelo fato de que, ao longo da história de escolarização dos povos indígenas, houve uma tendência de adoção de práticas que visam integrá-los à cultura dominante. É neste contexto que desenvolvemos uma reflexão acerca da educação escolar indígena.

Rossato (2002), analisando o papel da educação escolar entre os Kaiowá e Guarani em Mato Grosso do Sul, salienta as contradições enfrentadas com a inserção da escola e os impactos do processo de escolarização. Tal escola, imposta pelos karaí (brancos), leva para 
dentro dessas comunidades práticas que, muitas vezes, contrariam seus modos de ser e de viver, deixando de lado, saberes e processos próprios de aprendizagem. Para a autora:

[...] é no processo educativo de cada povo indígena que se reproduz aquilo que são ou que pensam de si mesmos. A educação indígena reflete o Nós (Ore, para os Kaiowá e Guarani), como componente da identidade, 'do nosso modo de ser' (ñande reko). Isto é, ela se insere dentro da reprodução e da produção da identidade, marcada por um Nós em movimento, histórico [...]

Tradicionalmente, a educação indígena dava-se através da participação na vida de uma comunidade educativa. Com o surgimento de agentes e instituições especializadas em educação, como a escola, essa situação se altera, gerando extrema tensão entre a comunidade educativa e a escola, evidenciando relações conflitivas e contradições (Rossato, 2002, p.38, 51).

Para Meliá (1979, p.17), "tentar identificar os aspectos relevantes da educação indígena não é tarefa fácil, dada a inter-relação entre a educação e todos os demais aspectos da cultura". Tassinari (2001) entende a escola em áreas indígenas como um espaço de "fronteira". Nela se dão processos de tradução e mediação de conhecimentos, onde diferentes regimes de conhecimento se encontram e são ressignificados.

A noção de fronteira, apresentada pela autora, baseia-se em espaços não muito delimitados, pois promovem intercâmbios entre populações, que se realizam sempre em movimento. "Trata-se de entender a escola indígena como um espaço de índios e não-índios e, assim, um espaço de angústias, incertezas, mas também de oportunidades e de criatividade" (Tassinari, 2001, p. 68). Nesta fronteira entre educação indígena e a educação escolar indígena, insere-se a discussão sobre o papel do ensino da matemática na formação de professores e nas escolas dessas comunidades.

É num cenário que se produz resistência e uma busca constante do estabelecimento de um diálogo intercultural. E nesse processo onde se busca soluções aos problemas enfrentados pela comunidade de educadores indígenas e não-indígenas, que emergem as tensões no campo do conhecimento. Assim como em todo o Brasil, em Mato Grosso do Sul, o Movimento dos Professores Guarani e Kaiowá levaram para as Universidades a necessidade da implantação de cursos para a formação de professores indígenas em nível superior.

Com o crescimento do número de professores indígenas no Curso de Formação de Professores em Nível Médio - Ára Verá (Espaço Iluminado), que objetiva formar professores indígenas Guarani e Kaiowá para atuarem nas séries iniciais do Ensino Fundamental, assim como o oferecimento nas escolas das aldeias indígenas dos Ensinos Fundamental e Médio, criou-se, por parte das comunidades, uma expectativa pela implantação de um curso superior específico para professores guarani e kaiowá.

A efetivação deste curso passou pela apresentação de um Projeto de Formação de Professores Indígenas em Nível Superior que vinha sendo formulado, desde 2003, em encontros com as comunidades e com a participação do Movimento de Professores Indígenas, de Universidades de Mato Grosso do Sul e de ONGs. A partir das demandas apresentadas por 
esse movimento, em 2006 a Universidade Federal da Grande Dourados - UFGD implantou o curso de Licenciatura Intercultural Indígena -Teko Arandu.

É importante ressaltar que o projeto deste curso foi levado à universidade pelas mãos dos professores indígenas, os quais participaram da elaboração da proposta do curso. Eles buscaram na instituição pública um espaço para a garantia de sustentabilidade étnica e de elaboração do conhecimento a partir de diferentes lógicas de compreensão do mundo.

A Licenciatura Indígena está organizada em quatro anos e meio de formação, sendo um ano e meio dedicado a uma formação comum, três dedicados à habilitação em uma área específica $^{11}$ escolhida por cada aluno. Entre as habilitações está a área Matemática, que prevê a formação de professores indígenas para atuarem no ensino de matemática nos anos finais do Ensino Fundamental e no Ensino Médio, em suas aldeias. O curso é organizado na perspectiva da pedagogia da alternância, o que possibilita a articulação de diferentes tempos e espaços no processo de formação.

No Projeto Pedagógico Curricular (PPC) do curso formação específica, na habilitação em Matemática se adota, enquanto princípio, um ponto de equilíbrio entre duas perspectivas. De um lado, uma perspectiva internalista da matemática, hoje prática predominante nos cursos de formação de professores de Matemática, nos quais prevalece a especificidade do conhecimento matemático eurocentrado, tido como verdadeiro. E de outro lado, uma perspectiva culturalista, na qual se supervaloriza os saberes próprios em nome de um almejado resgate, ou resistência, desconsiderando a inevitável dinâmica cultural consequente do encontro de culturas, da ocupação do mesmo espaço por sociedades diferentes (PPC Licenciatura Intercultural Indígena, 2012).

A formação de professores indígenas em nível superior, assume uma perspectiva intercultural, segundo a qual um dos desafios consiste em reconhecer as diferentes formas de produzir e comunicar conhecimentos, onde a Matemática, ao lado da língua materna, constitui-se num importante campo simbólico de resistência cultural. Em virtude disso, a Matemática foi definida, pelos indígenas, como uma das áreas específicas para a formação de professores. De acordo com o PPC, o curso focaliza, na formação dos professores indígenas, diferentes temáticas, tais como: Matemática, cultura e poder; Matemática, no mundo real; Matemática, desenvolvimento e mudança social na vida dos indígenas; Matemática, arte e arquitetura; Matemática e linguagem: universalidades e singularidades; Matemática, bilinguismo e educação, entre outros.

Atualmente, cerca de 40 professores indígenas Guarani e Kaiowá estão formados na habilitação Matemática deste curso. As discussões sobre as relações entre saberes nas escolas indígenas, neste artigo, são feitas a partir das falas de alguns destes professores formados, que buscam espaço nas escolas indígenas para atuação nos anos Finais do Ensino Fundamental e no Ensino Médio, nas áreas indígenas em que estas modalidades são oferecidas. Isso porque as disciplinas de ciências e matemática, nas escolas indígenas, ainda são ocupadas por professores não indígenas.

${ }^{11}$ No Núcleo Específico do curso de Licenciatura Indígena são oferecidas formações específicas em quatro grandes áreas: Ciências Sociais e Educação Intercultural, Linguagens e Educação Intercultural, Matemática e Educação Intercultural, Ciências da Natureza e Educação Intercultural. 
DOI: https://doi.org/ 10.20396/zet.v26il.8650893

\section{Relações entre saberes, interculturalidade e decolonialidade.}

A presença dos indígenas nos cursos de formação inicial de professores, mais especificamente nas Licenciaturas Interculturais Indígenas, nos remete a uma reflexão sobre as ações desenvolvidas no âmbito da formação de professores, em que o indígena assume um papel de pesquisador de suas próprias práticas e conhecimentos culturais. Estes cursos propõem uma abordagem que possibilite aos professores indígenas também assumirem o papel de propor outras práticas escolares, a partir da compreensão sobre diferentes aspectos no ensino e na aprendizagem no contexto da escola indígena. Dentre esses aspectos estão a escolha de quais saberes serão valorizados na escola e quais possibilidades de diálogo entre os diferentes saberes.

Para Tubino (2002), na interculturalidade “a palavra-chave é o diálogo". O diálogo pressupõe o reconhecimento e parte das desigualdades sociais, econômicas, políticas e de poder, com vistas a suprimi-las. O diálogo decorrente da ação entre diferentes formas de conhecimento tem influenciado no ensino de matemática nas escolas indígenas e na formação de professores indígenas. Nesse sentido, o processo de formação inicial e a reflexão das ações pedagógicas desenvolvidas, num espaço escolarizado, possibilita a compreensão sobre os diferentes aspectos do ensino e da aprendizagem de matemática, no qual se pressupõe que a formação do professor estabeleça um diálogo, na perspectiva da educação intercultural.

$\mathrm{Na}$ formação desenvolvida no curso de Licenciatura Intercultural Indígena - Teko Arandu, na habilitação em matemática, busca-se o desenvolvimento de uma ação pedagógica, segundo o pressuposto de que, no encontro entre grupos de culturas distintas, sejam intercambiados saberes. Nesta relação entre saberes distintos, são colocados alguns questionamentos, quando se trata da construção do conhecimento na formação de professores indígenas. Quais saberes os professores indígenas trazem para dialogar no seu processo de formação na universidade e quais saberes são valorizados no currículo das escolas indígenas?

Em algumas falas de professores indígenas podemos identificar alguns caminhos para analisar como eles entendem as relações entre saberes no currículo, e como vão construindo processos de novas práticas provenientes desta relação com a universidade. Estamos diante da questão que diz respeito às relações entre saberes, as quais se configuram em um movimento, de um lado e do outro, do indígena e do não indígena.

As investigações no campo da formação de professores indígenas de matemática, no interior das terras Guarani e Kaiowá, têm se constituído em um modo de explorar e conhecer como os povos indígenas utilizam os saberes próprios e como estabelecem relações com os saberes escolares nas dinâmicas que são próprias da escola indígena. Na universidade, ao longo do processo de formação destes professores, estes saberes defrontam-se com diferentes formas de conhecer. Nessa relação ficam explícitas as tensões no espaço acadêmico, diante da necessidade de considerar saberes que circulam no processo de formação a partir da diferença, ou seja, a partir de outras lógicas epistemológicas que se diferenciam das produzidas a partir da racionalidade ocidental. Esta tensão aparece na fala dos indígenas, ao refletirem sobre o papel da formação na universidade.

Vivo sempre pensando sobre entrar na faculdade gostaria de falar sobre o que senti durante este tempão quando entrei no Ará Verá e depois no Teko Arandu. Vou resumir em quatro eixos principais que eu tenho na minha vida para entender (...) o que seria este estudo na faculdade: primeira coisa é $\boldsymbol{e u}$ aprendi, não somente aprender 
como momento dentro do contexto desta faculdade, também o contexto Guarani e Kaiowá, a ciência Guarani e Kaiowá com os mais novos e mais velhos. Aprendi também, ... durante o estudo da faculdade, a ciência do ocidente, o conhecimento ao redor que precisa ser entendido. Isso é, a primeira coisa, que são o eixo que escrevi, é aprender a conhecer primeiro. O segundo eixo que escrevi é aprender a fazer tudo isso que eu aprendi com os povos guarani e kaiowá com os professores, colegas de faculdade, eu aprendi a fazer as coisas, a sistematizar a escrever com os professores (...) então, é a partir destes estudos que eu aprendi a escrever, interpretar, de fazer e praticar; então, o segundo eixo é aprender a fazer, isso que sempre anda junto com nós tem que aprender a fazer. Por exemplo, nunca mexi no computador, mas depois de entrar na faculdade eu mexi computador... então isso são fatos que podem fazer que eu tô aprendendo alguma coisa... que está dentro do nosso contexto. Terceiro é aprender a viver com este contexto .... da faculdade, da academia e também conviver com a sociedade Guarani e Kaiowá como intercultural. E o quarto eixo é aprender a ser isso. Então esses eu resumi (...) todas as coisas que aprendi, por exemplo, eu coloquei na prática junto com os professores, colegas, os rezadores, comunidade. Isso é o caminho pra mim, por exemplo, para entender mais cada vez o que é o estudo, (...) porque, quando no início vocês falou sobre a identidade, nós também estamos construindo uma identidade, Meliá falou, no contexto de seus discípulos, sobre o construção da identidade, que tipo de identidade, depois que eu termino o curso da faculdade, que tipo de identidade vou mostrar para a comunidade, como a comunidade vai me ver depois que eu termino este curso. Isso é uma grande preocupação eu tenho o que é sair da faculdade. Será que no final desse curso vou ser cacique (...) fazer guaxiré? É isso? Depois que terminar este curso, será que vou ser um doutor de estudo? Então isso também eu reflito muito, que quero falar e deixar, por exemplo, uma lacuna para dentro do contexto que nós estamos discutindo no grupo. E no final eu quero ler uma mensagem que nosso parente (...) escreveu, quando eu estava lendo estava pensando, fala assim:

[...] o sofrimento que cantamos entre todos nós, apesar de tudo nós não perdemos nossas memórias, nunca esquecemos de nosso pai criador que tudo fez para sermos felizes, nós estamos sofrendo sim em sua terra sagrada, mas este sofrimento não será para sempre, só vossa sabedoria infinita pode nos levar à justiça ...então esta sabedoria. (Professor Kaiowá, Enoque Batista ${ }^{12}$ ).

É importante ressaltar, na fala do professor Kaiowá, que a formação na universidade o fez um pesquisador de sua própria cultura, um conhecedor " $e$ u aprendi, não somente aprender como momento dentro do contexto desta faculdade, também o contexto Guarani e Kaiowá, a ciência Guarani e Kaiowá com os mais novos, mais velhos”.

Santos (2010) chama de "epistemicídio" a vasta destruição e subalternização de saberes próprios de diferentes povos causadas pelo colonialismo europeu. O processo de colonialismo produziu não só o domínio econômico, mas o domínio dos corpos, por meio da escravização e do genocídio, não só físico, mas também cultural.

Ao tratar destas relações de saberes presentes no processo de formação, os indígenas

\footnotetext{
${ }^{12}$ Enoque Batista é egresso da turma 2006, habilitação em Matemática. Professor da escola na aldeia Taquaperi, município de Coronel Sapucaia-MS. Esta transcrição é de uma fala que foi proferida por ele durante atividade de formação na Licenciatura Intercultural Indígena.
}

Zetetiké, Campinas, SP, v.26, n.1, jan./abr.2018, p.167-184

ISSN 2176-1744 
falam do avivamento de saberes que vinham sendo silenciados, subalternizados. E, neste processo de aprender sobre seu próprio povo, emergem saberes que estão ali, mas agora outros, já modificados. O mundo moderno impõe a cada um de nós, uma ideia de universalidade do saber ocidental. Isso não é diferente para os povos indígenas. O que tem sido produzido pelos povos indígenas, e mais especificamente pelos Guarani e Kaiowá, é um movimento de resistência a esse processo. Podemos entender que o fato de nomear os saberes próprios como ciência é gerado a partir das tensões de desigualdade entre esses saberes, ou seja, eles reconhecem na palavra "ciência" um lugar instituído discursivamente de poder. Chamar os saberes próprios de ciência representa um aspecto político, simbólico e epistemológico de resistência (Mendes, 2006).

Um outro ponto importante a destacar na fala do professor, ao se referir às práticas de conhecer no âmbito acadêmico, traz um entendimento de que conhecer e aprender é fazer, ou seja, não há uma separação entre conhecimento e ação, ou seja, saber é uma forma de agir. Nas palavras dele, é a partir destes estudos na universidade, que aprendeu "a escrever, interpretar, fazer e praticar [...] aprender a fazer, isso que sempre anda junto com nós, tem que aprender a fazer".

As relações entre saberes, estabelecidas no modelo imposto pelas estruturas, pelos sistemas de poder e pelos conhecimentos coloniais, são mantidas e reproduzidas pela universidade e, consequentemente, pela escola. E ainda guiam os modos de ser e de se perceber no mundo. Entretanto, no processo de interculturalidade, estas formas de ser e de perceber o mundo são produzidas a partir destes encontros de duas formas distintas de viver: "aprender a viver com este contexto [...] da faculdade, da academia e também conviver com a sociedade Guarani e Kaiowá como intercultural [...] aprender a ser”.

A formação de professores indígenas na universidade se depara com a necessidade de estabelecer relações entre epistemologias a partir de outros lugares de enunciação. De acordo com Mignolo e Walsh (2002), é preciso reconhecer que os saberes não se produzem em uma única região do globo, mesmo os saberes eurocêntricos são também locais:

[...] es necessário recordarlo, puesto que sabemos ya desde hace tiempo que todo pensamento está localizado, pero, a pesar de saber esto, hay una tendencia general a entender el pensamiento construido a partir de la historia y la experiencia europeas como si estuviera des-localizado". (Mignolo, 2007, p.33)

$\mathrm{O}$ processo de colonização estabeleceu um tipo de relação de poder em que o conhecimento se revela tal qual a economia; estão organizados a partir de centros de poder e de regiões subalternas, Norte e Sul (Santos, 2010). O discurso da modernidade criou a ilusão de que o conhecimento é universal, que não está ligado ao local.

Há, por parte dos indígenas, uma expectativa, em relação à formação na universidade, de que os saberes indígenas tenham um lugar. Isso gera, na universidade, uma instabilidade de cunho epistemológico e metodológico. Os indígenas vêm para a universidade com expectativas, questionamentos, mas também com propostas.

O estabelecimento do diálogo entre os saberes indígenas e os saberes da universidade, tem se tornado um desafio contínuo para os professores formadores e para os indígenas em 
formação, como assevera Carneiro da Cunha (2009, p. 313): “A política acadêmica e a política étnica caminham em direções contrárias. Mas a academia não pode ignorar que a "cultura" ressurge para assombrar a teoria ocidental". Mesmo que não haja uma intencionalidade, os saberes indígenas acabam atravessando as interações na universidade, nas ações pedagógicas do curso de formação. Esses atravessamentos geram tensões quanto ao perfil do professor indígena de matemática, pois a matemática presente no currículo das escolas indígenas ainda tem sido tratada como um conhecimento neutro e universal, a partir de uma racionalidade que não estabelece relações com os diferentes saberes (matemáticos) pertencentes a esses grupos. O ensino da matemática, da forma como está posto nas escolas indígenas, não tem relação com a cultura local. Desse modo, a racionalidade, imposta a partir de uma lógica homogeneizadora, deslegitima o professor indígena, bem como coloca em dúvida a sua formação com uma perspectiva intercultural.

Esta tensão também tem gerado efeitos na atuação desses professores, quando buscam assumir a disciplina de matemática nas escolas indígenas. Eles passam por uma formação inicial voltada a um perfil de professor para atuar em uma perspectiva intercultural, que propõe o diálogo entre diferentes formas de saber. Entretanto, ao chegarem na escola indígena, que ainda conta com a atuação de professores não indígenas, eles se deparam com uma organização curricular homogeneizadora, imposta via secretarias de educação. Em função do modelo que está posto, muitos indígenas declaram que, ao retornarem para as escolas indígenas, não assumem o ensino nas séries finais do ensino fundamental e no ensino médio, pois há um discurso corrente de que a licenciatura intercultural não prepara bem estes professores.

Este medo também advém do modelo de escola que está colocado para os indígenas. Existe um currículo com uma lógica para a qual não se sentem muito preparados. $\mathrm{O}$ Teko Arandu tem preparado os professores para atuarem em uma escola indígena diferenciada, com um currículo diferenciado. Muitos dos egressos do Teko podem não estar nem nos anos finais do Ensino Fundamental e nem no Ensino Médio, mas cumprem funções importantes na escola e na comunidade. Os modos de organização do Ensino Fundamental e Ensino Médio, as formas de saber que são predominantes, não favorecem a inserção destes professores. Muitos relatam que são tidos nas escolas como "malformados" no Teko. Isso leva a crer que o curso não está sendo um curso de boa qualidade. Estes argumentos me levam a crer que, de fato, a formação do Teko não atende este modelo de escola indígena, presente nas aldeias. (grifos meus) (Professor Guarani Kaiowá, Eliel Benites)

Walsh (2009) propõe falar de uma outra "ordem do conhecimento", com a possibilidade de abordar o problema educativo a partir de outra perspectiva que permita ir além das políticas educativas ou das propostas curriculares presentes nas escolas. Segundo ela, o currículo, que está ainda colocado para as escolas indígenas, contribuiu e segue contribuindo para a colonização do pensamento, a partir das noções de singularidade, objetividade, neutralidade da ciência, do conhecimento, da epistemologia, e da noção de que umas pessoas são mais aptas do que outras (Walsh, 2009). Para a autora, é necessário caminhar em direção a uma reformulação educativa, a partir de uma orientação decolonial, que implica trabalhar estrategicamente em diferentes frentes, incluindo a do conhecimento:

(...) discutir uma política epistêmica de interculturalidade, mas também epistemologias políticas e críticas no campo da educação, poderia servir para elevar 
DOI: https://doi.org/ 10.20396/zet.v26il.8650893

os debates em torno da interculturalidade para outro nível, passando de suas raízes na diversidade étnico-cultural para o problema de "Ciência" em si. Ou seja, para mostrar como a ciência, como um dos fundamentos centrais do projeto de modernidade/ colonialidade, contribuiu de forma vital para o estabelecimento e manutenção da ordem racial hierárquica histórica e atual, em que os brancos - Homens brancos europeus - permanecem no topo. (Walsh, 2009, p.206, tradução livre das autoras)

\section{Palavras Finais}

As falas dos professores guarani e kaiowá, egressos do curso de Licenciatura de Intercultural Indígena, nos remete às relações que estão colocadas entre as formas como os saberes circulam e são produzidos no âmbito do curso. Os professores indígenas, quando participam dos cursos, trazem suas concepções de corpo e de saber para o espaço da universidade, as quais transgridem as formas de organização do conhecimento no âmbito da instituição.

Assim, é importante reforçar que as relações entre saberes, estabelecidas no modelo imposto pelas estruturas, pelos sistemas de poder e pelos conhecimentos coloniais, são mantidas e reproduzidas nos espaços institucionais e, consequentemente, pelas escolas indígenas. Entretanto, quando os indígenas adentram estes espaços via licenciaturas interculturais, as quais são fruto dos movimentos indígenas, são gerados tensionamentos que colocam em questão as relações hierárquicas entre os saberes na lógica colonial. Desta forma, a interculturalidade e a decolonialidade são projetos que estão ligados à luta por uma escola indígena diferenciada, e sempre em construção, permeada por uma série de tensões.

\section{Referências}

Barros, M. C. D. M. (2004). A missão Summer Institute of Linguistics e o indigenismo latino-americano: história de uma aliança (décadas de 1930 a 1970). Revista de Antropologia, 47(1), 45-85. Retirado em 10 de março, 2009, de: http://www.scielo.br/pdf/ra/v47n1/a02v47n1.pdf.

Brasil (1996). Lei no 9.394, de 20 de dezembro de 1996. Estabelece as diretrizes e bases da educação nacional. Brasília, DF. Retirado em 10 de outubro, 2017 de: http://www.planalto.gov.br/ccivil_03/leis/L9394.htm.

Brasil (1998). Constituição da República Federativa do Brasil de 1988. Brasília. Retirado de: file:///D:/Cliente/Downloads/constituicao_federal_35ed.pdf.

Brasil (1999a). Resolução 03/99 de 10 de novembro de 1999. Fixa Diretrizes Nacionais para o funcionamento das escolas indígenas e dá outras providências. Brasília: MEC/CNE. $\begin{array}{lllll}\text { Retirado } & \text { em } & 0 & \text { de }\end{array}$ http://portal.mec.gov.br/cne/arquivos/pdf/CEB0399.pdf.

Brasil (1999b). Parecer 14/99 do Conselho Nacional de Educação de 14 de setembro de 1999. Dispõe sobre as Diretrizes Nacionais da Educação escolar Indígena. Brasília: MEC/CNE. Retirado em 10 de outubro, 2017, de: http://portal.mec.gov.br/sesu/arquivos/pdf/leis2.pdf.

Brasil (2000). Lei n. 9.984, de 17 de julho de 2000. Dispõe sobre a criação da Agência Nacional de Águas - ANA, entidade federal de implementação da Política Nacional de Recursos Hídricos e de coordenação do Sistema Nacional de Gerenciamento de 
Recursos Hídricos, e dá outras providências. Brasília, DF. Retirado em 10 de abril, 2007, de: http://www.planalto.gov.br/ccivil/Leis/L9984.htm.

Brasil (2001). Lei 10.172 - 9 de janeiro de 2001. Aprova o Plano Nacional de Educação e dá outras providencias. Brasília: MEC. Retirado em 10 de outubro, 2017, de: http://www2.camara.leg.br/legin/fed/lei/2001/lei-10172-9-janeiro-2001-359024publicacaooriginal-1-pl.html.

Brasil (2009). Decreto Presidencial 6.861 de 27 de maio de 2009. Dispõe sobre a Educação Escolar Indígena, define sua organização em territórios etnoeducacionais, e dá outras providências. Brasília, DF. Retirado em 10 de outubro, 2017, de: http://www2.camara.leg.br/legin/fed/decret/2009/decreto-6861-27-maio-2009-588516norma-pe.html.

Brasil (2015). Resolução $\mathrm{N}^{\circ} 2$ de $1^{\circ}$ de julho de 2015. Define as Diretrizes Curriculares Nacionais para a formação inicial em nível superior (cursos de licenciatura, cursos de formação pedagógica para graduados e cursos de segunda licenciatura) e para a formação continuada. Brasília: MEC.

Brito, R. P. S. (2012). Apropriação de práticas de numeramento em um contexto de formação de educadores indígenas. Dissertação de Mestrado em Educação, Conhecimento e Inclusão Social. Belo Horizonte: Universidade Federal de Minas Gerais.

Cunha, M. C. (2009). Cultura com aspas. São Paulo, Cosac \& Naify.

Carneiro da Cunha, M. (2009). Cultura com aspas. São Paulo, Cosac \& Naify.

Certeau, M. (1995). A cultura no plural. Trad. Enid Abreu Dobránszky. 4. ed. Campinas: Papírus.

Correa, R. A. (2001). A Educação Matemática na formação de professores indígenas: os professores Ticuna do Alto Solimões. Tese de doutorado em Educação. Campinas: Universidade Estadual de Campinas.

Domingues, K. C. M. (2007). Interpretação do papel, valor e significado da formação do professor indígena do Estado de São Paulo. Dissertação mestrado em Educação. São Paulo: Universidade de São Paulo.

Ferreira, M. K. L. (2001). A educação escolar indígena: um diagnóstico crítico da situação no Brasil. In M. K. L. Ferreira \& A. L. Silva (orgs.), Antropologia, História e Educação: a questão indígena e a escola (pp.71-111). São Paulo: Global.

Grupione, L. D. B. (2006). Contextualização no campo da formação de professores indígenas no Brasil. In L. D. B. Grupione (Org.), Formação de professores indígenas no Brasil: repensando trajetória. Brasília: MEC.

Leite, K. G. (2014). Nós mesmos e os outros: etnomatemática e interculturalidade na escola indígena paiter. Tese de Doutorado em Educação em Ciências e Matemática. Cuiabá: Universidade Estadual de Mato Grosso. Retirado em 15 de julho, 2017, de: http://www.ufmt.br/ufmt/unidade/userfiles/publicacoes/41cadca38a3966fc32d26eda119 8a69c.pdf. 
Lopez Bello, S. E. (2000). Etnomatemática: relações e tensões entre as distintas formas de explicar e conhecer. Tese Doutorado em Educação. Campinas: Universidade Estadual de Campinas.

Mendes, J. R. (1995). Descompassos na interação professor-aluno na aula de matemática em contexto indígena. Dissertação de mestrado em Linguística Aplicada. Campinas: Universidade Estadual de Campinas. Disponível em: http://repositorio.unicamp.br/handle/REPOSIP/269525.

Mendes, J. R. (2001). Ler, escrever e contar: práticas de numeramento-letramento dos Kaiabi no contexto de formação de professores índios no Parque Indígena do Xingu. Tese de doutorado em Linguística Aplicada - Educação Bilíngue. Campinas: Universidade Estadual de Campinas. Disponível em: http://repositorio.unicamp.br/handle/REPOSIP/270211.

Mendes, J. R. (2006). Aspectos políticos e simbólicos na apropriação do discurso da Etnomatemática: o caso dos professores Kaiabi do Parque Indígena do Xingu. In G. Knijnik, F. Wanderer \& C. J. Oliveira (Org.), Etnomatemática, currículo e formação de professores (364-376). Santa Cruz do Sul: Editora Santa Cruz do Sul.

Mendes, J. R. (2007). Numeracy and Literacy in a Bilingual Context: Indigenous Teachers Education in Brazil. Educational Studies in Mathematics, 64 (2), 217-230.

Mendonça, A. A. N. (2007). Práticas pedagógicas nas aulas de matemática: um estudo exploratório nas escolas Xacriabá. Dissertação de mestrado em Educação. Belo Horizonte: Universidade Federal de Minas Gerais.

Mignolo, W. (2000). Diferencia colonial y razón posoccidental. In S. Castro Gomes (ed.), La reestructuracíon de las ciencias sociales en America Latina. Bogotá: Centro editorial Javeriano. Disponível em: http://waltermignolo.com/wpcontent/uploads/2013/03/DiferenciaColonial.pdf).

Mignolo, W., \& Walsh, C. (2004). Las geopolíticas de conocimiento y colonialidad del poder (Entrevista a Walter Mignolo). En C. Walsh, F. Schiwy \& S. Castro-Gómez (Edts), Indisciplinar las ciencias sociales. Geopolíticas del conocimiento y colonialidad del poder. Perspectivas desde lo Andino. Quito: UASB/Abya Yala, en prensa.

Monte, N. L. (2000). Os outros, quem somos? Formação de professores indígenas e identidades interculturais. Cadernos de Pesquisa, (111), 7-29. Disponível em: http://www.scielo.br/pdf/cp/n111/n111a01.pdf.

Monteiro, A., \& Mendes, J. R. (2014). A etnomatemática no encontro entre práticas e saberes: Convergências, tensões e negociação de sentidos. Revista Latinoamericana de Etnomatemática, 7(3), 55-70.

Oliveira, M. A. M. (2009). Práticas vivenciadas na constituição de um curso de licenciatura indígena em Matemática para as comunidades indígenas Guarani e Kaiowá de Mato Grosso do Sul. Mestrado em Educação Matemática. Campo Grande: Universidade Federal do Mato Grosso do Sul.

Parra, A., Mendes, J. R., Vilavicencio, M., \& Valero, P. (2016). Mathematics Education in Multilingual Contexts for the Indigenous Population in Latin America. In R. Barwell, P. Clarkson, A. Halai, M. Kazima, J. Moschkovich, N. Planas, M. Phakeng, P. Valero 
DOI: https://doi.org/ 10.20396/zet.v26il.8650893

\& V. Ubillús. (Orgs.), Mathematics Education and Language Diversity (pp. 67-84). Berlim: Springer.

Prada, F., \& López, L. E. (2005). Educación Superior y Descentralización Epistemológica. In: Anais das I Conferencia Internacional sobre Ensino Superior Indígena: construindo novos paradigmas. Barra do Bugres: UNEMAT.

Quijano, A. (1992). colonialidad y modernidad/racionalidad. Perú Indígena, 13(29): 11-20.

Rossato, V. L. (2002). Os Resultados da Escolarização Entre os Kaiowá e Guarani em Mato Grosso do Sul: "Será o letrado ainda um dos nossos? Dissertação de Mestrado em Educação. Campo Grande: Universidade Católica Dom Bosco.

Santos, B. V. S. (2010). Para além do pensamento abissal: das linhas globais a uma ecologia de saberes In B.V.S. Santos \& M. P. Meneses, (Org.), Epistemologias do Sul (31-83). São Paulo: Cortez.

Schaden, E. (1974). Aspectos fundamentais da cultura Guarani. 3. ed. São Paulo: EDUSP.

Tassinari, A. M. I. (2001). Escola Indígena: novos horizontes teóricos, novas fronteiras de educação. In A. L. Silva \& A. M. Ferreira (Orgs.), Antropologia, História e Educação, a questão indígena e a escola (pp. 44-77). São Paulo: MARI/FAPESP/Global Editora.

Tubino, F. (2002). Entre el multiculturalismo y la interculturalidad: más allá de la discriminación positiva. In N. Fuller (ed.), Intercultualidad y Política. Desafíos y posibilidades (pp. 51-76). Lima: Red para el Desarrollo de las Ciencias Sociales.

Vietta, K. (1998). Perícia judicial - Processo 96158-8: Relatório Final da Perícia realizada na Área Indígena Panambizinho, Distrito de Panambi, Município de Dourados, Mato Grosso do Sul. Campo Grande (mimeo).

Walsh, C. (2004). Geopolíticas del conocimiento, interculturalidad y descolonialización. Boletín ICCI-ARY Rimay, 6 (60), 1-3.

Walsh, C. (2009). Interculturalidad crítica e educación intercultural. In Seminário Interculturalidad y Educación Intercultural realizado de 9-11 de marzo de 2009. La Paz: Organizado pelo Instituto Internacional de Integracióndel Convenio Andrés Bello.

Walsh, C. (2009). Interculturalidad, Estado, Sociedad Luchas (De)Coloniales de Nuestra Época. Quito: Universidad Andina Simón Bolívar/Ediciones Abya-Yala. Disponível em: http://clar.org/assets/interculturalidadestadosociedad.pdf.

Recebido em: 31/10/2017

Aprovado para publicação em: 03/04/2018 